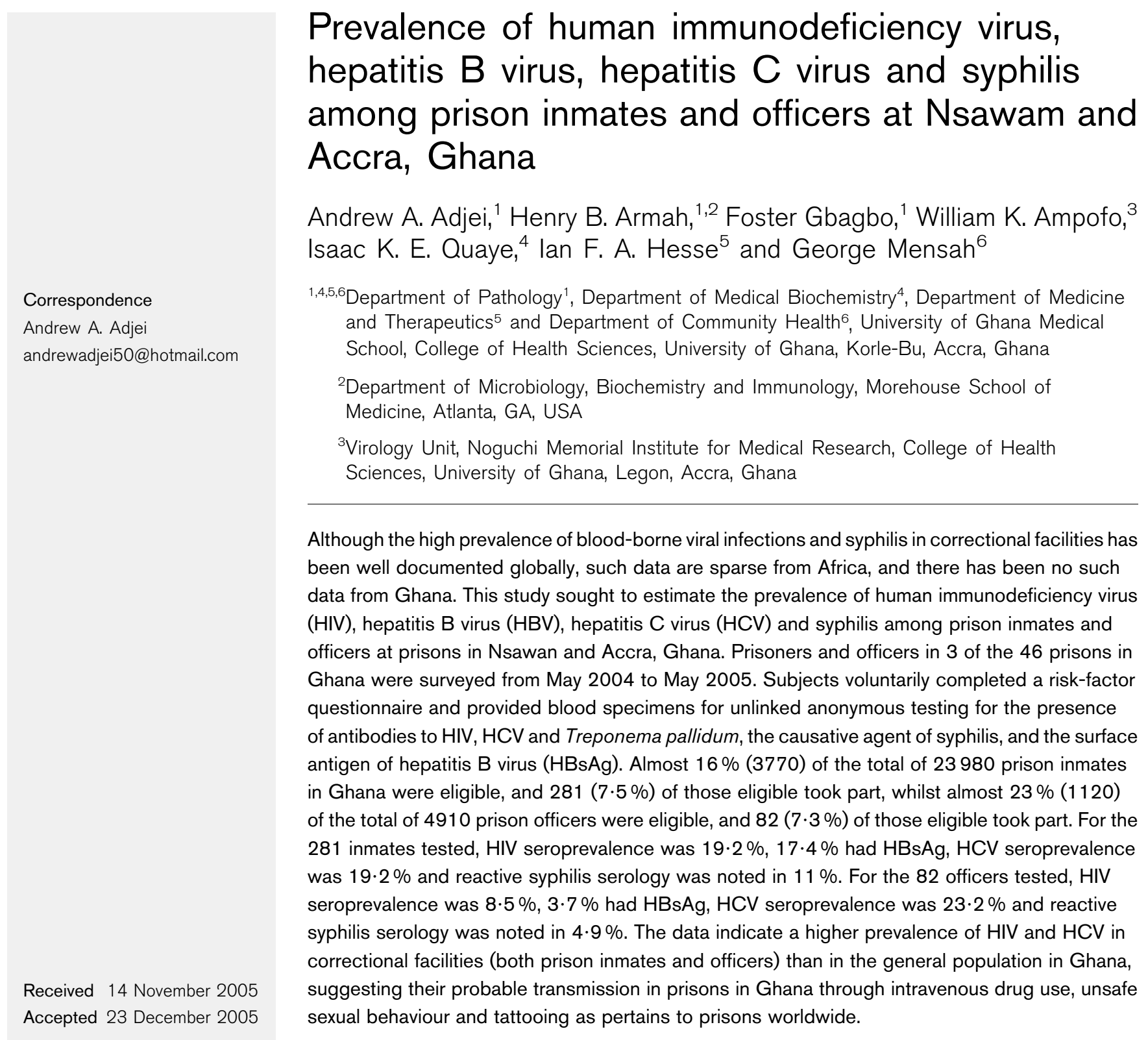

\title{
Prevalence of human immunodeficiency virus, hepatitis B virus, hepatitis $C$ virus and syphilis among prison inmates and officers at Nsawam and Accra, Ghana
}

\author{
Andrew A. Adjei, ${ }^{1}$ Henry B. Armah, ${ }^{1,2}$ Foster Gbagbo, ${ }^{1}$ William K. Ampofo, ${ }^{3}$ \\ , 5 - \\ and Therapeutics ${ }^{5}$ and Department of Community Health6, University of Ghana Medical \\ College of Health Sciences, University of Ghana, Korle-Bu, Accra, Ghana \\ 'Department of Microbiology, Biochemistry and Immunology, Morehouse School of \\ Medicine, Atlanta, GA, USA \\ Virology Unit, Noguchi Memorial Institute for Medical Research, College of Health \\ Sciences, University of Ghana, Legon, Accra, Ghana
}

\begin{abstract}
Although the high prevalence of blood-borne viral infections and syphilis in correctional facilities has been well documented globally, such data are sparse from Africa, and there has been no such data from Ghana. This study sought to estimate the prevalence of human immunodeficiency virus (HIV), hepatitis B virus (HBV), hepatitis $\mathrm{C}$ virus (HCV) and syphilis among prison inmates and officers at prisons in Nsawan and Accra, Ghana. Prisoners and officers in 3 of the 46 prisons in Ghana were surveyed from May 2004 to May 2005. Subjects voluntarily completed a risk-factor questionnaire and provided blood specimens for unlinked anonymous testing for the presence of antibodies to HIV, HCV and Treponema pallidum, the causative agent of syphilis, and the surface antigen of hepatitis B virus ( $\mathrm{HBsAg}$ ). Almost $16 \%$ (3770) of the total of 23980 prison inmates in Ghana were eligible, and $281(7.5 \%)$ of those eligible took part, whilst almost $23 \%$ (1120) of the total of 4910 prison officers were eligible, and $82(7 \cdot 3 \%)$ of those eligible took part. For the 281 inmates tested, HIV seroprevalence was 19.2\%, 17.4\% had HBsAg, HCV seroprevalence was $19.2 \%$ and reactive syphilis serology was noted in $11 \%$. For the 82 officers tested, HIV correctional facilities (both prison inmates and officers) than in the general population in Ghana, sexual behaviour and tattooing as pertains to prisons worldwide.
\end{abstract}

\section{INTRODUCTION}

The relation between incarceration and the high transmission of blood-borne viruses, such as human immunodeficiency virus (HIV), hepatitis B virus (HBV), hepatitis C virus (HCV) and syphilis, in prisons has been known for several years (Catalan-Soares et al., 2000; Haber et al., 1999; Heimberger et al., 1993; Mutter et al., 1994; Stark et al., 1997), and injecting drug use is the most commonly reported risk factor (Alizadeh et al., 2005; Massad et al., 1999; Taylor et al., 2000; Wield et al., 2000). The other risk factors identified for the higher prevalence of these infections in prisoners are previous imprisonment, tattooing and

Abbreviation: HBsAg, surface antigen of hepatitis B virus. high-risk sexual behaviours (Haber et al., 1999; Massad et al., 1999; Skoretz et al., 2004; Veeken, 2000). There is growing evidence that HIV, HBV and HCV infections have actually been transmitted to individuals while they were in prison (Haber et al., 1999; Hutchinson et al., 1998; Mutter et al., 1994; Skoretz et al., 2004; Stark et al., 1997; Taylor et al., $1995,2000)$, although there is also evidence that some had the infection before they were sent to prison. Data on the prevalence of HIV, HBV, HCV and syphilis in prisons are scanty in Africa, and no such information exists on prisoners in Ghana. Outside the prison setting in Ghana, the prevalence of HIV infection is between 1.5 and $3.8 \%$ among blood donors (Ampofo et al., 2002; Candotti et al., 2001; Sarkodie et al., 2001), 3.1\% among the general female population of Accra, Ghana (Duda et al., 2005) and 2.7\% 
among parturients in Accra, Ghana (Damale et al., 2005). The reported prevalence of the surface antigen of hepatitis $\mathrm{B}$ virus (HBsAg) is $15.3 \%$ among blood donors in Ghana (Sarkodie et al., 2001), and $15 \cdot 8$ and $20.9 \%$ among children (Martinson et al., 1996) and the general population (Martinson et al., 1998), respectively, in a rural district in Ghana. The prevalence rate of HBsAg among parturients or pregnant women in Accra, Ghana, increased from $6.4 \%$ in 1994 (Acquaye \& Mingle, 1994) to $10.5 \%$ in 2005 (Damale et al., 2005). The seroprevalence of HCV is between $1 \cdot 3$ and $8.4 \%$ among blood donors in Ghana (Ampofo et al., 2002; Candotti et al., 2001; Sarkodie et al., 2001; WansbroughJones et al., 1998), 5•4\% among children in a rural district in Ghana (Martinson et al., 1996) and 2.5\% among parturients in Accra, Ghana (Lassey et al., 2004). The seroprevalence of Treponema pallidum, the causative agent of syphilis, is between 7.5 and $13.5 \%$ among blood donors in Ghana (Adjei et al., 2003; Ampofo et al., 2002), and 5.6\% among antenatal and gynaecological clinic attendants in Accra, Ghana (Apea-Kubi et al., 2004).

About 24000 individuals are currently incarcerated in the 46 prisons in Ghana. Systematic surveillance of the infectious diseases HIV, HBV, HCV and syphilis in the incarcerated population in Ghana is completely absent, and none of the 46 prisons in Ghana have a program for routine HBV and HCV testing, immunization and treatment. Conditions prevailing in our prisons are poor with overcrowding, poor nutrition and inadequate healthcare. Anecdotal reports indicate that a great deal of unsafe sexual activity (including sodomy, homosexual and lesbian activities, paid sex and sexual favours to prison officers), drug injection and needle sharing occurs among prisoners in Ghana. The aim of this study was to determine the prevalence of HIV, HBV, HCV infections and syphilis among prisoners and prison officers at Nsawam Medium Security Prison (in Nsawam, Ghana) and James Fort Prison and James Camp Prison (both in Accra, Ghana), and to compare this with that of the general Ghanaian population (mainly healthy blood donors and pregnant women).

\section{METHODS}

Study site. The study was carried out between the months of May 2004 and May 2005 among prison inmates and officers at the Nsawam Medium Security, James Fort and Ussher Fort (now James Camp) prisons in Ghana. These three prison centres, the largest in the country, serve the Accra metropolitan area, and the whole country. The Nsawam Medium Security Prison, which was designed for a maximum of 600 prisoners, now accommodates over 2000 inmates with a mean of 65 occupants in the dormitory-type rooms intended for a maximum of 20 , and a mean of 4 occupants in the rooms originally intended for single occupancy. The James Fort and James Camp prisons, which were each designed for a maximum of 300 prisoners, now accommodate over 900 inmates each with a mean of 55 occupants in the dormitory-type rooms intended for a maximum of 15 , and a mean of 4 occupants in the rooms originally intended for single occupancy. The mean ratio of inmates to sanitary facilities for their use (both bath and toilet rooms) is 100 inmates per sanitary room. The mean male to female ratio is $2 \cdot 5$ to 1 . The protocol for the study was approved by the Ethical and Protocol Review Committee of the University of Ghana Medical School, Accra, Ghana.

Study population. Subjects for this study were both male and female prison inmates and officers at the Nsawam Medium Security, James Camp and James Fort prisons. After an explanation of the purpose of the study, all prison inmates and officers were invited to participate. They were informed that the study was confidential and that the information provided by the prisoners would not affect their incarceration status. A total of 363 individuals, 281 inmates and 82 officers (105 from Nsawam Medium Security Prison, 167 from James Fort Prison and 91 from James Camp Prison), joined in the research. Written informed consent was obtained from each participant, and the information regarding the protocol and informed consent was presented at the appropriate literacy level. The medical records of each consenting participant were reviewed to ascertain whether they had been previously tested for the infections under investigation, the results of the previous testing, and any evidence of treatment for symptoms consistent with the particular infection. The study was conducted in a confidential manner and random unique study-generated numbers were employed to identify the participants.

Questionnaire. All the 363 consenting participants completed a structured questionnaire assessing socio-demographic characteristics, sexual and drug histories, and a risk factor profile for the infections under investigation. Physical examination was done to evaluate the general health condition of each participant.

Sample collection and serological analysis. Blood samples (about $10 \mathrm{ml}$ ) were collected from each of the 363 consenting participant in plain tubes. Samples were centrifuged and the serum kept at $-20{ }^{\circ} \mathrm{C}$ until analysed. Sera were tested at the Virology Unit, Noguchi Memorial Institute for Medical Research, for the presence of antibodies to HIV 1 and 2 (ELISA and Western Blot; Abbot and Cambridge Biotech, respectively), antibodies to HCV (ELISA; Abbot), and antibodies to T. pallidum [T. pallidum particle agglutination (TPPA) test; Serodia Fujirebio] and HBsAg (monoclonal, ELISA; Abbot), in accordance with the respective manufacturer's instructions. Repeatedly reactive specimens by ELISA were assayed by Western blotting.

Statistical analysis. Data were entered into a database and analysed statistically using the EPI-INFO 2003 statistical software package (CDC). Fisher's test was used to determine any statistically significant differences in prevalence between the prison inmates and officers, between the sexes, and between the different age groups. A $P$ value $<0 \cdot 05$ was considered significant.

\section{RESULTS}

Between May 2004 and May 2005, 363 subjects [82 prison officers (56 males, 26 females) and 281 prison inmates (237 males, 44 females), aged 17-84 years (mean age 36.02 \pm $11.01 \mathrm{SD})]$ were recruited to participate in the study. The inmates were in prison for various reasons, the most common being stealing $(76 \cdot 1 \%)$, armed robbery $(54 \cdot 6 \%)$, rape $(45 \cdot 9 \%)$, narcotics $(41 \cdot 1 \%)$, murder $(35 \cdot 9 \%)$, fraud $(25 \cdot 9 \%)$, defilement $(17 \cdot 6 \%)$ and assault $(9 \cdot 8 \%)$. The inmates had various educational backgrounds, with 190 $(67 \cdot 6 \%)$ having had primary or basic education only as compared to $147(97 \cdot 4 \%)$ officers who had secondary and tertiary education. Of the inmates, $83.2 \%$ used marijuana, $7 \cdot 3 \%$ used cocaine, $5 \cdot 2 \%$ used heroin and $4 \cdot 2 \%$ used phencyclidine (PCP). However, none of the officers 
admitted using any such drugs. Homosexuality was reported by $30.8 \%(73 / 237)$ of the male inmates, with 11 of them reporting initiation of this behaviour in the prison environment. Lesbianism was reported by $22.7 \%(10 / 44)$ of the female inmates, with 5 of them reporting initiation of this behaviour in the prison environment. Thirty-five inmates had their skins tattooed in prison, using shared needles and ink. The most common sign on physical examination was pallor in $80.4 \%$ of the inmates, followed by skin lesions (superficial fungal and bacterial infections, and scabies) in $14.6 \%$ of the inmates and hypertension (blood pressure $\geqslant$ $140 / 90 \mathrm{mmHg}$ ) in $12.9 \%$ of the inmates. The most common symptom by far was loss of appetite in $42.9 \%$ of the inmates, followed by skin rashes in $19 \cdot 6 \%$ of the inmates.

Table 1 shows the results of the testing for the prevalence of antibodies to HIV, HBV, HCV and syphilis among the prison inmates and officers at the three prison centres. Of the 281 inmates tested from all the 3 prisons, HIV seroprevalence was $19 \cdot 2 \%, 17 \cdot 4 \%$ had HBsAg, HCV seroprevalence was $19 \cdot 2 \%$ and reactive syphilis serology was noted in $11 \%$. Of the 82 officers tested from all the 3 prisons, HIV seroprevalence was $8.5 \%, 3 \cdot 7 \%$ had HBsAg, HCV seroprevalence was $23 \cdot 2 \%$ and reactive syphilis serology was noted in $4.9 \%$. The seroprevalence of HIV, HBV, HCV and syphilis among the inmates and officers at the Nsawam Medium Security Prison was significantly higher $(P<0 \cdot 05)$ than the seroprevalence observed at the James Fort and James Camp Prisons, except for seroprevalence of HCV among inmates and syphilis among officers at the James Camp Prison. Generally, the seroprevalence of all four infections was significantly higher $(P<0 \cdot 05)$ in the inmates than among the officers, except for the seroprevalence of $\mathrm{HCV}$ among officers at Nsawam Medium Security Prison and syphilis among officers at James Camp Prison. Except for one inmate who was seropositive for all four infections (HIV, HBV, HCV and syphilis), all the other positive results were found in different individuals. Among both the prison inmates and officers, the seroprevalence of all four infections showed no statistically significant differences $(P>0 \cdot 05)$ between the two sexes, and between the various age groups (data not shown).

\section{DISCUSSION}

Knowledge of the prevalence and distribution of bloodborne viruses and sexually transmitted diseases (STDs) in different parts of the world, and particularly in Africa, is important for the planning of preventive measures and the development of vaccination programmes. Furthermore, the comparison of their prevalence among prisoners, prison officers and the general population in the same geographical area is important to provide a basis for action, and changes in public health policy, education and clinical practice. The purpose of this study was to determine the seroprevalence of HIV, HBV, HCV and T. pallidum among prison inmates and officers in prisons in Accra and Nsawan, Ghana, and to compare this with previous data from healthy blood donors, pregnant women and the general population in Ghana. The present study, which is believed to be the first in the country, provides definitive evidence for an 'outbreak' of HIV and HCV occurring within our prison centres. The results showed a significantly higher seroprevalence of HIV and $\mathrm{HCV}$ among the prison inmates and officers, as compared to the seroprevalence of these infections previously reported in the general public in Ghana, mainly healthy blood donors and pregnant women (Ampofo et al., 2002; Candotti et al., 2001; Damale et al., 2005; Duda et al., 2005; Lassey et al., 2004; Martinson et al., 1996; Sarkodie et al., 2001; Wansbrough-Jones et al., 1998). However, the seroprevalence of HBsAg and syphilis among the prison inmates and officers was comparable to that previously reported in the general Ghanaian population (Acquaye \& Mingle, 1994; Adjei et al., 2003; Ampofo et al., 2002; Apea-Kubi et al., 2004; Damale et al., 2005; Martinson et al., 1996, 1998; Sarkodie et al., 2001). The present study supports previous reports that prisoners represent a high-risk group for blood borne diseases and STDs (Alizadeh et al., 2005; CatalanSoares et al., 2000; Heimberger et al., 1993; Skoretz et al., 2004; Taylor et al., 1995; Wield et al., 2000).

The observation of the increased prevalence of antibodies to HIV and HCV among both prison inmates and officers, sometimes even higher in the officers than the inmates, is strongly presumptive evidence of intra-prison transmission

Table 1. Prevalence and relation of positive serological results among inmates and prison officers (both males and females) in Nsawam, James Fort and James Camp prisons, Ghana

$N$, total number tested; $n$, number of positives.

\begin{tabular}{|c|c|c|c|c|c|c|c|c|c|}
\hline & \multicolumn{3}{|c|}{ Nsawam } & \multicolumn{3}{|c|}{ James Fort } & \multicolumn{3}{|c|}{ James Camp } \\
\hline & $\begin{array}{c}\text { Inmates } \\
N=72 \\
n(\%)\end{array}$ & $\begin{array}{c}\text { Officers } \\
\begin{array}{c}N=33 \\
n(\%)\end{array}\end{array}$ & $P$ value & $\begin{array}{c}\text { Inmates } \\
N=133 \\
n(\%)\end{array}$ & $\begin{array}{c}\text { Officers } \\
\begin{array}{c}N=34 \\
n(\%)\end{array}\end{array}$ & $P$ value & $\begin{array}{c}\text { Inmates } \\
N=76 \\
n(\%)\end{array}$ & $\begin{array}{c}\text { Officers } \\
\begin{array}{c}N=15 \\
n(\%)\end{array}\end{array}$ & $P$ value \\
\hline HIV & $37(51 \cdot 4)$ & $2(6 \cdot 1)$ & $<0 \cdot 05$ & $9(6 \cdot 8)$ & $1(2 \cdot 9)$ & $<0 \cdot 05$ & $8(10 \cdot 5)$ & $1(1 \cdot 3)$ & $<0.05$ \\
\hline $\mathrm{HBV}$ & $15(20 \cdot 8)$ & $6(18 \cdot 2)$ & $>0 \cdot 05$ & $25(18 \cdot 8)$ & $0(0 \cdot 0)$ & $<0 \cdot 05$ & $9(11 \cdot 8)$ & $1(1 \cdot 3)$ & $<0 \cdot 05$ \\
\hline Syphilis & $12(16 \cdot 7)$ & $1(3 \cdot 0)$ & $<0 \cdot 05$ & $14(10 \cdot 5)$ & $0(0 \cdot 0)$ & $<0 \cdot 05$ & $5(6 \cdot 6)$ & $2(13 \cdot 3)$ & $<0 \cdot 05$ \\
\hline
\end{tabular}


of HCV infection between prison inmates and officers. This may have been due to a number of factors, including the frequent movement of prisoners and officers between establishments, often with little notice, and the high rate at which prisoners return to prison after release. The rate at which prisoners return to prison after release is known to be particularly high among drug users, indicating that this group of individuals may be source of intra- and interprison transmission of HIV and HCV. A significant number of the prison inmates used illicit drugs, especially marijuana $(83 \cdot 2 \%)$, practised homosexuality $(30 \cdot 8 \%)$ and lesbianism $(22 \cdot 7 \%)$. In this study, $83 \cdot 2,7 \cdot 3,5 \cdot 2$ and $4 \cdot 2 \%$ of the inmates reported marijuana, cocaine, heroin and PCP use, respectively. Growing evidence also suggests that in general, prisoners are more sexually active in the community than the general population, reporting a higher number of partners and lower use of condoms (Catalan-Soares et al., 2000; Skoretz et al., 2004; Veeken, 2000). Most prisoners have the high-risk behaviours for the transmission of these infections. Besides illicit drug use, unsafe sex and homosexuality, prisoners frequently tattoo their skins out of boredom, and in the process share needles and ink. These high-risk behaviours place prisoners at increased risk of infection with blood-borne viruses in comparison to the rest of the population (Catalan-Soares et al., 2000; Skoretz et al., 2004; Veeken, 2000). It may seem reasonable, therefore, to suggest that most of the infections might have occurred before incarceration. But this is unlikely, because none of the seropositive individuals had symptoms during the period of the study, even though the majority (192 out of 281) of the inmates had been in prison for about 10 years. Similarly, most of the prison officers had been working in the same prison settings for the past 4 years.

The higher seroprevalence of HIV and HCV in prison inmates and officers, than among the general population of mainly blood donors and pregnant women, was probably due to the higher proportion of individuals with a prior history of intravenous drug use and high-risk sexual behaviours amongst the former group. The lower socioeconomic and educational status of the prisoners compared to the officers, and the poor conditions prevailing at the prison centres, may have contributed to the higher prevalence in the prisoners than the officers for most of the infections. The significantly higher seroprevalence of these infections seen in the Nsawam prison compared to the other 2 prisons may be attributable to the fact that the Nsawam prison has a much larger prisoner population (2000 compared to 900 in the other prisons) with more overcrowding (65 in a dormitory compared to 55 in a dormitory in the other prisons). As a rule, there are inadequate medical facilities and staff in the prisons in Ghana, and access to appropriate care outside the Ghana prison system is very difficult for the inmates. Inmates and officers of correctional facilities in Ghana, therefore, constitute a high-risk group for HIV, HBV, HCV and syphilis infections, and counselling, routine screening, HBV vaccination and treatment are recommended.
The implications of these findings for HIV, HBV, HCV and syphilis public health education are obvious. This high level of seropositivity of HIV and HCV in our prison setting raises concerns about the need for preventive measures, such as condom distribution, education, vaccination or immunization within the prisons. From our study, it is also obvious that a great deal of unsafe sexual activity and drug use occurs in our prisons, and with the high rate of HIV and HCV seropositivity among inmates, it is clear that inmates have a substantial risk of contracting these infections while incarcerated. This has important implications for the monitoring and control of these infections in the rest of the society, as most persons sent to jail in Ghana remain in prison for relatively short periods then become part of the general population again and might be 'fertile reservoirs' for the spread of these infections. The markedly increased prevalence of HCV among the prison inmates and officers requires that we place an increased prominence on $\mathrm{HCV}$ prevention in our educational agenda for curtailing infectious diseases in Ghana. We recommend that all individuals who are jailed must be screened to determine their status with regards to the listed infections, so one can draw a line between the relative spread from within and what is carried in from outside. Our data indicate that all four infections, HIV, $\mathrm{HBV}, \mathrm{HCV}$ and syphilis, are problems for the prisoners as well as the officers. We were particularly surprised at the high prevalence of $\mathrm{HCV}$, which has received very little attention in our educational agenda for curtailing infectious diseases in Ghana. The scope of the current study did not allow us to determine whether the inmates acquired the diseases while in prison or carried them in. Further studies are underway to determine the modes of transmission, and to institute interventional measures. Although, the prison inmates and officers participating in our study cannot be considered representative of all the prisons in Ghana, the results reported herein have significant implications for penal and public health officials, suggesting the importance of introducing policies to prevent transmission of HIV, $\mathrm{HCV}, \mathrm{HBV}$ and syphilis during and following incarceration. These policies must include testing programmes in prisons, which should be seen as an opportunity to improve the health status of the infected prison inmates and officers, and prevent further transmission of the infectious agents, within and without the prisons.

\section{ACKNOWLEDGEMENTS}

We are grateful to the staff of the Ghana Prison Service, Accra, Ghana for their cooperation and assistance. For technical, logistical and clerical support, we thank Paul Boamah, Samuel Kudadzi, Loretta Antwi, Emelia Ampah, Emmanuel Ametepe, Ama Afrah and Cecilia Smith, all of whom are from the University of Ghana Medical School. This work was funded by research grants from the Ghana AIDS Commission (GAC), Accra, Ghana, and the Health Research Unit, Ghana Health Service, Ministry of Health, Accra, Ghana through the Ghana-Dutch Collaborative Program for Health Research and Development. 


\section{REFERENCES}

Acquaye, J. K. \& Mingle, J. A. A. (1994). Hepatitis B viral markers in Ghanaian pregnant women. West Afr J Med 13, 134-137.

Adjei, A. A., Kudzi, W., Armah, H., Adiku, T., Amoah, A. G. B. \& Ansah, J. (2003). Prevalence of antibodies to syphilis among blood donors in Accra, Ghana. Jpn J Infect Dis 56, 165-167.

Alizadeh, A. H. M., Alavian, S. M. \& Jafari, K. \&Yazdi N. (2005). Prevalence of hepatitis $\mathrm{C}$ virus infection and its related risk factors in drug abuser prisoners in Hamedan, Iran. World J Gastroenterol 11, 4085-4089.

Ampofo, W., Nii-Trebi, N., Ansah, J. \& 8 other authors (2002). Prevalence of blood-borne infectious diseases in blood donors in Ghana. J Clin Microbiol 40, 3523-3525.

Apea-Kubi, K. A., Yamaguchi, S., Sakyi, B., Kisimoto, T., OforiAdjei, D. \& Hagiwara, T. (2004). Neisseria gonorrhoea, Chlamydia trachomatis, and Treponema pallidum infection in antenatal and gynecological patients at Korle-Bu Teaching Hospital, Ghana. Jpn J Infect Dis 57, 253-256.

Candotti, D., Sarkodie, F. \& Allain, J. P. (2001). Residual risk of transfusion in Ghana. Br J Haematol 113, 37-39.

Catalan-Soares, B. C., Almeida, R. T. P. \& Carneiro-Proietti, A. B. F. (2000). Prevalence of HIV-1/2, HTLV-I/II, hepatitis B virus (HBV), hepatitis $\mathrm{C}$ virus (HCV), Treponema pallidum and Trypanosoma cruzi among prison inmates at Manhuacu, Minas Gerais State, Brazil. Rev Soc Bras Med Trop 33, 27-30.

Damale, N. K. R., Lassey, A. T. \& Bekoe, V. (2005). Hepatitis B virus seroprevalence among parturients in Accra, Ghana. Int J Gynaecol Obstet 90, 240-241.

Duda, R. B., Darko, R., Adanu, R. M. K., Seffah, J., Anarfi, J. K., Gautam, S. \& Hill, A. G. (2005). HIV prevalence and risk factors in women of Accra, Ghana: results from the Women's Health Study of Accra. Am J Trop Med Hyg 73, 63-66.

Haber, P. S., Parsons, S. J., Harper, S. E., White, P. A., Rawlinson, W. D. \& Lloyd, A. R. (1999). Transmission of hepatitis C within Australian prisons. Med J Aust 171, 31-33.

Heimberger, T. S., Chang, H. G., Birkhead, G. S., DiFerdinando, G. D., Greenberg, A. J., Gunn, R. \& Morse, D. L. (1993). High prevalence of syphilis detected through a jail screening program. A potential public health measure to address the syphilis epidemic. Arch Intern Med 153, 1799-1804.

Hutchinson, S. J., Goldberg, D. J., Gore, S. M., Cameron, S., McGregor, J., McMenamin, J. \& McGavigan, J. (1998). Hepatitis B outbreak at Glenochil prison during January to June 1993. Epidemiol Infect 121, 185-191.
Lassey, A. T., Damale, N. K., Bekoe, V. \& Klufio, C. A. (2004). Hepatitis $C$ virus seroprevalence among mothers delivering at the Korle-Bu Teaching Hospital, Ghana. East Afr Med J 81, 198-201.

Martinson, F. E., Weigle, K. A., Mushahwar, I. K., Weber, D. J., Royce, R. \& Lemon, S. M. (1996). Seroepidemiological survey of hepatitis B and C virus infections in Ghanaian children. J Med Virol 48, 278-283.

Martinson, F. E., Weigle, K. A., Royce, R. A., Weber, D. J., Suchindran, C. M. \& Lemon, S. M. (1998). Risk factors for horizontal transmission of hepatitis B virus in a rural district in Ghana. Am J Epidemiol 147, 478-487.

Massad, E., Rozman, M., Azevedo, R. S. \& 7 other authors (1999). Seroprevalence of HIV, HCV and syphilis in Brazilian prisoners: preponderance of parenteral transmission. Eur J Epidemiol 15, 439-445.

Mutter, R. C., Grimes, R. M. \& Labarthe, D. (1994). Evidence of intraprison spread of HIV infection. Arch Intern Med 154, 793-795.

Sarkodie, F., Adarkwa, M., Adu-Sarkodie, Y., Candotti, D., Acheampong, J. W. \& Allain, J. P. (2001). Screening for viral markers in volunteer and replacement blood donors in West Africa. Vox Sang 80, 142-147.

Skoretz, S., Zaniewski, G. \& Goedhuis, N. J. (2004). Hepatitis C virus transmission in the prison/inmate population. Can Commun Dis Report 30, 16-26.

Stark, K., Bienzle, U., Vonk, R., Guggenmoos, I. \& Holzmann, I. (1997). History of syringe sharing in prison and risk of hepatitis $B$ virus, hepatitis $\mathrm{C}$ virus, and human immuno-deficiency virus infection among injecting drug users in Berlin. Int J Epidemiol 26, 1359-1366.

Taylor, A., Goldberg, D., Emslie, J. \& 10 other authors (1995). Outbreak of HIV infection in a Scottish prison. $\mathrm{Br}$ Med $J$ 310, 289-292.

Taylor, A., Goldberg, D., Hutchinson, S., Cameron, S., Gore, S. M., McMenamin, J., Green, S., Pithie, A. \& Fox, R. (2000). Prevalence of hepatitis $\mathrm{C}$ virus infection among injecting drug users in Glasgow 1990-1996: are current harm reduction strategies working. J Infect 40, 176-183.

Veeken, H. (2000). Lurigancho prison: Lima's "high school" for criminality. Br Med J 320, 173-175.

Wansbrough-Jones, M. H., Frimpong, E., Cant, B., Harris, K., Evans, M. R. \& Teo, C. G. (1998). Prevalence and genotype of hepatitis C virus infection in pregnant women and blood donors in Ghana. Trans R Soc Trop Med Hyg 92, 496-499.

Wield, A. R., Gill, O. N., Bennett, D., Livingstone, S. J., Parry, J. V. \& Curran, L. (2000). Prevalence of HIV, hepatitis B, and hepatitis C antibodies in prisoners in England and Wales: a national survey. Commun Dis Public Health 3, 121-126. 